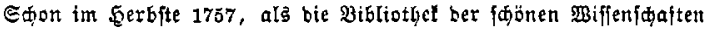

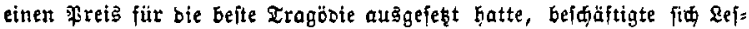
fing thit bem Sujet einer bürgetlifen Birginia, ber et ben Ittel $\mathbb{E}$ milia Balotti gegeben batte. Gr arbeitete febr lartgiam, "alle freben Tagc fieben Beilen." פBas er sabon fertig Eradte, verwarf or in ber Folge twieber unb lehrte erft zeben jahre fpäter, alo er in 5ुamburg bie Drama=

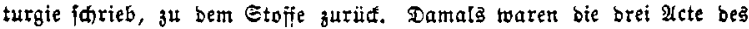
alter Entwurfes z̧war ifion auf bie übliđen fünf ertweitert, aber bie Arbeit war io argelegt, baß fie urr gefpiclt, nie gebrudt werben follte. Gs toar rod leine Drfina in bem Stüfe.

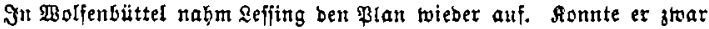

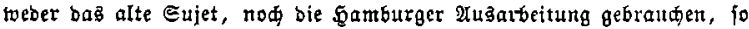
twitb bof bie $2 \mathfrak{n l a g e}$ im $2 \amalg g e m e i n e n$ geblieben fein, bie Tluflofung bes Fodtermorbes butd ben Bater it mobernere Berbältniffe, abgelöst vont ben politifien Batwerf, has bei ber freien Erfinbung nur ftörenb ober bemment wirlen lonnte. Erft in bieje Bearbeitung wurbe bie Miolle ber Bräfin Drfuta aufgenommen, in toelder bie Gofleute in syraunfwheig, bie Reffing nidit wohl wollten, Büge ber Miarlife Branconi zu erlenten

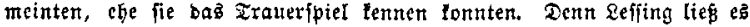

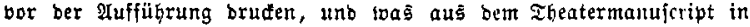
Döbbelins Befis berlauten modtc, lonnte rur ungenau fein. Lim bem Berebe ein Gube zu madien, fanote Refijng bie fertigen Bogen bis in ben bierten dufzug birect on ben alten serzog, unb erbot fid, falls berielbe

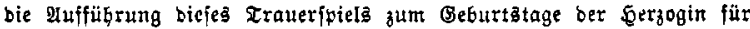
unfdiflid balte, biejelbe unter irgenb einem leidjt zu finbenben Borwanbe 3u bintertreiben, ba er nidit gern bas Beringfte thun ober geideben

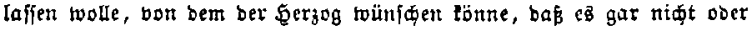

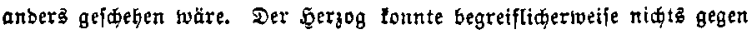

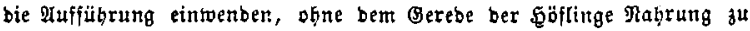
geber. Das tein Brumb bazu sorfanber geivefen toäre, lontte bamit

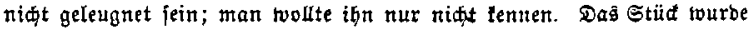
zum exfenmale am geburtatage ber ferzogin, 13. Dära 1772, von ber Döbbelinfujen Befellidaft in Braunfकịeig aufgeführt unb bie Darftellung joL zu Döbbelints beften gebört Gaben. Reffing woḩnte loeber biejer, nod

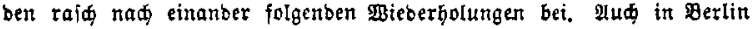




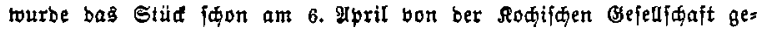
geben, bod biz 1781 nur neunmal. Die Berliner Freunbe fatten allerlei Bebentlipleiten, bie zum Theil bis auf bie Blegentwart immer nieber aufgeworfen werben. 2hber bas Stüd ift getwaltiger getwefer, als alle cin= würfe bagegen unb hat fie alle überbauert. $\Im a$ in ber neueren geit hat

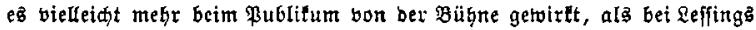
Beitgenofien, bie bei aller Sdüßzung für ben Didter bod nidit ben ßes fpect, ber aus ber Zotalität bon seffings setfturgen entipringt, auf bas einzeIne Etild übertrugen unb, anftatt es gelten zu Infien unb baran zu lernen, to fie nidit betwinbern tonnten, alts biejem ober jenem theoreti= foren Syjtem baran zu tabeln fanden. Zwei Puntte fitb utleugbar aud

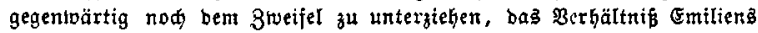
зum Brinjen unb bas Berfalten bes Baterö gegen bie Todjer. Es ift angebeutet, bas Emilia mit einer Reigung für ben ßrinzen zu ringen habe unb fid in ji由 felbjt nidst fider fühle, biejelbe auf bie Dauer, troß $i$ ḩrer beffern Heberzeugung, zu umerbriiden. Damt wäre ber $\mathfrak{B a t e r}$ viel=

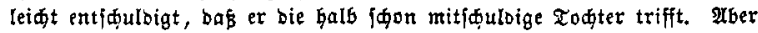
es ifit burd nidts angebeutet, baß er von ber beginnerben Mitjdulb feites sinbes itberzengt iit, unb bann hatte er teinen Grunb, bas ifulb: lofe mäbdien zu erntorben, auf bas ber färift lein Berbredent ber Be= walt ober ber Berfügrung an if̧r begehen lönne. Sn bem Ealberonfiłen Ridter von 3alamea, ber in bielen Bejiegungen mit bem Reffinglden

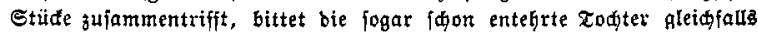
um ben Tob bon Baterhanb; ber Bater aber weigert benfelben unb metß jeḩr wobl, wen er als ben Equlbigen zu treffen hat, nidit bas̉ opfer (unb Emilia lann nur möglidertoeife ein Dpfer werten), fonbern ben હđlädter bez Dpfers. Dazu, baß Oboarbo ben Prinzen ober ben Suppler und Piorbftifter Marineli prmorbete, war \&effing bei aller Entfकloffenbeit bow niळt entidlofien genatg. Det Morb ber Birginia burd bie Ganb bes Baters, ber ein Redit äber Reben unb Tob hatte, was Dboarbo nidt hat, Glieb boh nidt olyne vetwirrenbe Folgen für bas beutfकe Stüd. -

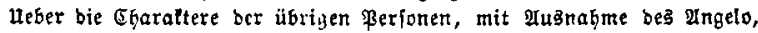
ift nidts su fagen, als bas fie, je genauer fie ftubirt werben, befto mög=

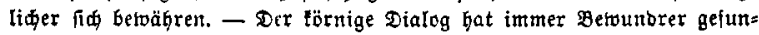

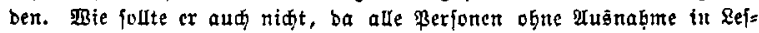
fings bialeftijiem Stile reben, uto biejer, tocnn aud niđit ber abjolute Etil, bod ein burçaus inbivibuell bollenbeter ift.

A. Boebets. 


\section{(Emilia Galotti.}

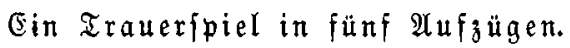

1772. 